\title{
La versión digital estática de un patrimonio cambiante: documentar el arte urbano y público
}

\author{
Carmen Moral Ruiz | Dpto. Didácticas Integradas, Universidad de Huelva \\ URL de la contribución <www.iaph.es/revistaph/index.php/revistaph/article/view/4885>
}

Dentro de la dinámica natural por la que se procede a la conservación y restauración de un bien patrimonial está la premisa de promover el mantenimiento de un estado de conservación que muestre una imagen concreta de dicho bien. Aunque en la esencia del bien patrimonial esté la tendencia a la modificación por el envejecimiento natural de sus materiales, se procura estabilizar su imagen durante un tiempo considerable de cara al espectador que la observará. En estos casos, la documentación de dicho patrimonio se nos revela más sencilla, dado que lo que documentamos, por ejemplo fotográficamente, será, con ciertos cambios, lo que se quiere mantener en el tiempo. Si la obra desaparece dicha documentación será el testigo para el futuro.

Tal y como reseñan en la introducción a este debate Elena García y Laura Luque, el espacio de la ciudad ofrece infinitas posibilidades y dichas posibilidades pueden anidar de forma duradera en nuestro imaginario cultural. Por lo tanto, si tomamos conciencia del mismo y forma parte de nuestra cultura, las obras que pertenecen a la categoría de arte urbano y público deberán ser transmitidas en el futuro, sobre todo considerando la posible destrucción de muchas de ellas en un mañana no tan lejano.

Las redes sociales promueven la globalización en este caso incluso del arte urbano. Ese arte urbano que cuando sale de lo urbano para entrar en lo virtual deja en el camino el devenir que el tiempo ejerce sobre la obra para promover una imagen congelada de la misma. Pero entonces, ¿lo dejamos desaparecer sin ni siquiera tener la oportunidad de documentar?, al menos una imagen fija, aunque esa imagen sólo nos hable de una experiencia pasada. A raíz de la pandemia por COVID-19 el registro virtual de aquello que se encontraba en la calle y que había quedado fuera de nuestro alcance nos acercaba por un instante a lo perdido. Por ello, dicha documentación fue más allá de la motivación de conservación para el futuro y se convirtió en un elemento necesario y útil en el presente, para no olvidar ese entorno urbano cercano que estuvo vetado.

Tomando en consideración la inclusión de estas manifestaciones en nuestra clasificación social como patrimonio, se hace necesario ir más allá y abordar su conservación y difusión para la posteridad. En este sentido, podemos actuar por diversas vertientes. Una de las cuales es la documentación digital de dicho patrimonio, para que al menos de forma virtual perdure como imagen cultural de aquello que fue y que puede haber desaparecido. En el caso del arte urbano, tal y como refieren las coordinadoras del debate Elena García y Laura Luque, estamos ante una preservación de estas manifestaciones mediante la no intervención, promoviendo una evolución natural de la obra en relación con su contexto. La documentación de las mismas no permitirá su evolución y tampoco será capaz de recrear el espacio para el que fueron ideadas. Es por esto que tanto la conservación como la documentación de estas obras es controvertida y las opiniones son variables según los profesionales a los que hagamos referencia (Luque Rodrigo 2016).

Sin embargo, el uso de internet y de lo digital como medio alternativo no solo como documentación sino como medio de creación ya está en proceso como, por ejemplo, en la exposición titulada The Digital Street en la galería de arte contemporáneo Taby (González Vargas 2021). Con esta, entre otras iniciativas, entendemos que la visión que del arte urbano se tiene en la sociedad está cambiando, observándose también un aumento de su aceptación (Luque Rodrigo y Moral Ruiz 2021). En 
este sentido, volviendo a la digitalización, entendemos que aporta al menos una consecuencia positiva y es el acercamiento a distintos niveles de estas manifestaciones artísticas urbanas. Por ello, la creación de una imagen digital, desde el punto de vista de la conservación y restauración, nos ayuda a mantener al menos esa manifestación en la retina de la sociedad como medio de difusión y reconocimiento.

A la hora de conseguir una imagen para documentar este tipo de patrimonio podemos acudir a ciertas herramientas digitales que registran estas manifestaciones artísticas que están en muchas ocasiones determinadas por el carácter efímero. Esta documentación debe ser rigurosa y ser capaz de documentar no sólo el aspecto material sino también ciertas morfologías que en el caso del arte urbano y público pueden ser muy complejas (Moral Ruiz y Luque Rodrigo 2021). Según refiere Martín Talaverano (2014), la documentación gráfica que se genera debe servir para posteriores procesos de investigación, conservación y difusión del bien. Por lo tanto, una de las herramientas fundamentales para estos registros puede ser la técnica fotogramétrica. Esta técnica es aquella

$\equiv$ ELPAİS

CULTURA

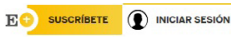

'The Digital Street', la alternativa en internet al arte urbano

Una galería nacida en la pandemia exhibe el trabajo de ocho artistas de cuatro continentes en una muestra "postmuralista"

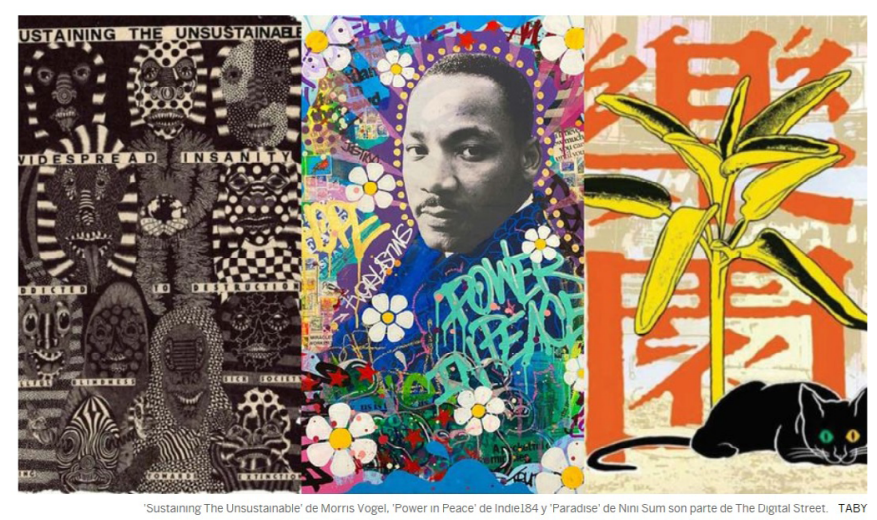

Exposición The digital Street en la galería de arte contemporáneo Taby. El País, 10 de marzo de 2021

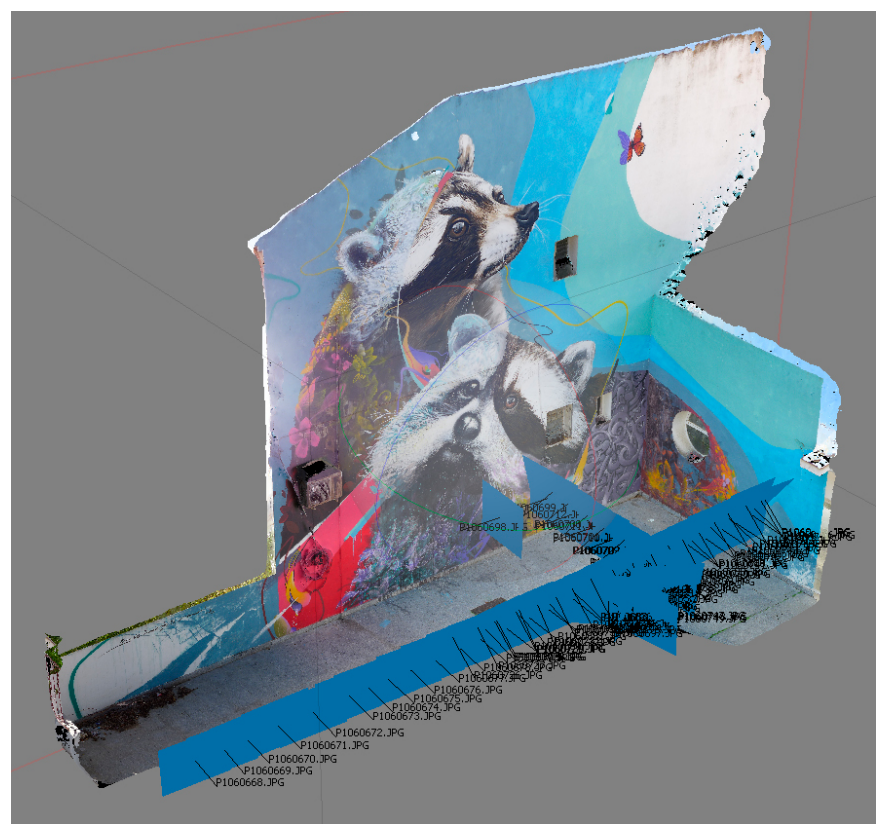

Ejemplo de barrido fotográfico con imágenes tomadas en azul y modelo resultante de la obra Inflexiones (Kraser y Ernesto Maranje) del Festival Art Sur (La Victoria, Córdoba) mediante software Photoscan ${ }^{\circledR}$ | imagen Carmen Moral Ruiz

que permite la medición de cualquier objeto a través de una serie de procesos sobre imágenes que muestren el objeto a documentar en perspectiva (Almagro Gorbea 2004). Hay varios sistemas que utilizan esta base fotográfica, entre los cuales se encuentra la fotogrametría convergente a través de bloques de imágenes en la que se basa el software Photoscan ${ }^{\circledR}$ utilizado para la elaboración de modelos tridimensionales.

La documentación digital del patrimonio urbano y público se refleja como necesaria aunque compleja por todos los elementos que se unen a dicho patrimonio y que no pueden ser reflejados en dicha documentación. A pesar de su complejidad y debido a la creciente notoriedad de estas manifestaciones se revela como adecuada la documentación mediante modelos tridimensionales. Estos modelos aportan información tridimensional del espacio y posibilitan la creación de proyecciones ortogonales a través de las cuales, entre otras acciones, se pueden realizar mediciones de los elementos del modelo que pueden servir para conocer el estado de conserva- 
a debate Dilemas del arte urbano como patrimonio

| coordinan Elena García Gayo y Laura Luque Rodrigo

ción del mismo. A pesar de que la imagen que generen sea estática y no nos permita observar su evolución, al menos nos deja entrever su estética inicial con la posibilidad de establecer comparativas posteriores para entender su devenir.

\section{BIBLIOGRAFÍA}

- Almagro Gorbea, A. (2004) Fotogrametría y Restitución I y II. Máster de Restauración del Patrimonio Histórico, Área 1, El conocimiento. Murcia: Universidad Politécnica de Cartagena, pp. 279-301

- González Vargas, J. (2021) 'The Digital Street', la alternativa en internet al arte urbano. El País, 10 de marzo de 2021. Disponible en: https://elpais.com/cultura/2021-03-10/thedigital-street-la-alternativa-en-internet-al-arte-urbano.html [Consulta: 28/03/2021]

- Luque Rodrigo, L. (2016) Arte relacional en la calle. Casos de conservación colectiva. Ge-Conservación, vol. 10, pp. 117125. Disponible en: https://doi.org/10.37558/gec.v10i0.405 [Consulta: 25/03/2021]

- Luque Rodrigo, L. y Moral Ruiz, C. (2021) El arte urbano como patrimonio inmaterial. Posibilidades para su protección y difusión. En: I Simposio anual de Patrimonio Natural y Cultural ICOMOS España. Valencia: Editorial Universitat Politècnica de València, pp. 57-64. Disponible en: http://hdl.handle. net/10251/160166 [Consulta: 29/03/2021]

- Martín Talaverano, R. (2014) Documentación gráfica de edificios históricos: principios, aplicaciones y perspectivas. Arqueología de la Arquitectura, n. ${ }^{\circ} 11$, pp. 1-26 Disponible en: http://arqarqt.revistas.csic.es/index.php/arqarqt/article/ view/164 [Consulta: 05/04/2021]

- Moral Ruiz, C. y Luque Rodrigo, L. (2021) Técnicas de investigación y catalogación del arte urbano desde la transdisciplinariedad: aplicaciones y retos de futuro. En: I Simposio anual de Patrimonio Natural y Cultural ICOMOS España. Valencia: Editorial Universitat Politècnica de València, pp. 73-81. Disponible en: http://hdl.handle.net/10251/160178 [Consulta: 29/03/2021] 